\title{
PREVALENCIA DE VAGINITIS Y VAGINOSIS BACTERIANA EN PERSONAL POLICIAL DE LA PROVINCIA DE ICA, PERÚ
}

\author{
Elizabeth Hernández-Rios ${ }^{1,2}$, a.
}

1. Sanidad de la Fuerzas Policiales. Ica. Perú.

a. Bióloga.

\section{RESUMEN}

Objetivo: Determinar la prevalencia de vaginitis y vaginosis bacteriana en el personal policial de la provincia de Ica, Perú. Material y Métodos: Se realizó un estudio de tipo descriptivo y transversal, en personal policial de la provincia de Ica constituida por 80 mujeres. Resultados: Al evaluar las características macroscópicas de la secreción vaginal se encontró, en relación al tipo: $48,8 \%$ blanquecina, $23,8 \%$ amarillo verdosa, $12,5 \%$ blanco grisáceo y $15 \%$ amarillento; en cuanto a la cantidad: $58,8 \%$ fue regular, $23.8 \%$ y escasa; con respecto a la consistencia: $41,3 \%$ espumosa, $31,3 \%$ homogénea-adherente y grumosa $27,5 \%$. Al evaluar el olor, $42,5 \%$ tenía olor normal, $40 \%$ maloliente. Mediante coloración Gram se halló gran negativos: una cruz en el $45 \%$, dos cruces en $42,5 \%$; gran positivos: una cruz en $41.3 \%$, dos cruces en $26.3 \%$ y ninguno en $32.5 \%$; lactobacilos: una cruz en $27.5 \%$, dos cruces en 55; Mediante coloración Giemsa se halló positividad en $77,5 \%$ de las muestras estudiadas. En el $27,5 \%$ de las mujeres se halló Trichomona vaginalis en la secreción vaginal, en $12,5 \%$ Gardenella y en $11,2 \%$ Candida sp. Conclusiones: La prevalencia de vaginitis es $38,75 \%$ y la prevalencia de vaginosis bacteriana fue 12,50\%. (Rev. méd. panacea 2011; 1:40-43).

Palabras clave: Vaginosis bacteriana, tricomoniasis, candidiasis.

\section{PREVALENCE OF VAGINITIS AND BACTERIAL VAGINOSIS IN POLICE PERSONNEL FROM ICA PROVINCE, PERU}

\begin{abstract}
Objective: To determine the prevalence of vaginitis and bacterial vaginosis in female personal police in the city of Ica. Materials and Methods: A descriptive-transversal investigation was realized in the city of Ica in 80 female police . Results:. At macroscopic characteristics of vaginal discharge were found these types: $48.8 \%$ white, $23.80 \%$ greenish yellow, $12.5 \%$ grayish white and $15.0 \%$ off-white yellowish; in terms of amount: $58.8 \%$ regular, low in $23.8 \%$ and abundant at $17.5 \%$; about the consistency: $41.3 \%$ foam, $31.3 \%$ homogeneous, adherent and $27.5 \%$ lumpy. In assessing the odor: $42.5 \%$ normal, $40.0 \%$ malodorous and $17.5 \%$ smelled fishy. Gram staining found Gram negatives: a cross in $45.0 \%$, two crosses in $42.5 \%$ and $12.5 \%$ none, Gram positives: a cross at $41.3 \%$, two crosses in $26.3 \%$ and $32.5 \%$ none, lactobacilli: a cross in $27.5 \%$, two crosses in $55.0 \%$ and $17.5 \%$ none. By Giemsa staining was found positive in $77.5 \%$ of the samples. In $27.50 \%$ women, Trichonoma vaginalis was found in vaginal discharge, in $12.50 \%$ Gardenells and in $11.25 \%$ Candida sp. Conclusions: The prevalence of vaginitis is $38.75 \%$ and the prevalence of bacterial vaginosis was $12.50 \%$. (Rev. méd. panacea 2011;1:40-43).
\end{abstract}

Key words: Bacterial vaginosis, candidiasis, trichomoniasis.

\section{INTRODUCCIÓN}

Una las causas más frecuentes en la consulta ginecológica son las infecciones vaginales, las que se distribuyen en tres grupos dependiendo de los agentes microbianos que las producen: 1) la vaginosis bacteriana producida por la asociación entre Gardnerella vaginalis, microorganismos anaerobios y Mycoplasma spp, 2) vulvovaginitis candidiásica ocasionada por Candida albicans y 3) otras especies del género y la tricomoniasis vaginal, producida por Trichomonas vaginalis ${ }^{(1)}$.
La vaginosis bacteriana es caracterizada por abundante flujo espeso de olor a "pescado", considerándose como factores predisponentes: el inicio temprano de las relaciones sexuales, los dispositivos intrauterinos, el embarazo, así como con la utilización frecuente de duchas vaginales, su detección temprana y tratamiento es importante a fin de evitar complicaciones posteriores (enfermedad pélvica inflamatoria, infertilidad, embarazo ectópico), infección del recién nacido y nacimientos prematuros $^{(2)}$.

Las especies de Cándida se asocian a vulvovaginitis, sobre todo en ciertas etapas del ciclo menstrual o cuando la 
paciente ha recibido dosis continuadas de antimicrobianos, presentándose frecuentemente un flujo característico designado como de "leche cortada" acompañado de intenso prurito, disuria y enrojecimiento de la mucosa vaginal y el epitelio vulvar ${ }^{1}$. Se estima que hasta un $75 \%$ de las mujeres sexualmente activas sufren candidiasis vaginal al menos una vez en la vida y entre el 5 a $10 \%$ de ellas la padecen en forma recurrente (tres o más episodios en un año) ${ }^{(3,4)}$

Trichomonas vaginalis es un protozoo flagelado causante de una de las enfermedades más comunes de transmisión sexual en humanos, las manifestaciones clínicas son: flujo amarillo espumoso y maloliente, comezón y disuria; aunque hay mujeres que pueden no presentar ningún síntoma son capaces de infectar a su pareja, la tricomoniasis puede aumentar la susceptibilidad de una mujer a contraer la infección por VIH si está expuesta al virus, asimismo las mujeres embarazadas que tienen tricomoniasis pueden dar a luz bebés prematuros o con bajo peso ${ }^{(5,6)}$.

En la práctica clínica, las infecciones vaginales se diagnostican de acuerdo a la sintomatología y características del flujo vaginal $y$, la mayoría de veces, se inicia un tratamiento empírico. Sin embargo, es importante diagnosticar y tratar oportunamente estas entidades pues a pesar de ser benignas pueden dar lugar a complicaciones graves $^{(7)}$.

El objetivo de este estudio fue determinar la prevalencia de vaginitis y vaginosis bacteriana en el personal policial femenino de la ciudad de lca, identificando al agente causal mediante el examen microbiológico.

\section{MATERIAL Y MÉTODOS}

Se realizó una investigación de tipo observacional, transversal y descriptivo, durante los meses de setiembre y diciembre del 2009

La población estudiada fue el personal policial femenino de la provincia de Ica. se consideró como criterio de inclusión el ser mujeres sexualmente activas, que hayan aceptado someterse a las pruebas mediante la firma del consentimiento informado y, como criterios de exclusión: el ser mujeres que se negaran a participar del estudio, haber recibido antibiótico con un mes de antelación, haberse realizado duchas vaginales 24 horas antes del examen o que estuvieran menstruando.

La muestra final de participantes fue de 80 mujeres, a quienes se les realizó la toma de muestras de flujo vaginal con dos hisopos estériles, de las paredes vaginales laterales $\mathrm{y}$ fondo de saco posterior. Las muestras se recolectaron en el Servicio de Ginecología y luego se enviaron al laboratorio de análisis clínicos de la Sanidad de las Fuerzas Policiales,

Uno de los hisopos se colocó en un tubo de ensayo con 1 $\mathrm{ml}$ de solución salina $0,9 \%$ estéril, para investigar, en el sedimento, la presencia de Trichomonas vaginalis. Con el segundo hisopo se colocó la muestra en tres portaobjetos para investigar: a) hifas y/o pseudohifas mediante la tinción con $\mathrm{KOH}$ al $10 \%$, b) observar morfología bacteriana y realizar el diagnóstico de vaginosis bacteriana mediante coloración Gram y c) detección de Trichomonas vaginalis mediante coloración Giemsa. El test de aminas se efectuó añadiendo 3-5 gotas de $\mathrm{KOH}$ al $10 \%$ en la segunda torunda.

El primer hisopo sirvió también para realizar el cultivo de levaduras en Agar Sabouraud Dextrosa (Merck, S.A.), las que se incubaron a $37^{\circ} \mathrm{C}$, durante 72 horas; en la lectura se observó la morfología y el color de las colonias. La observación microscópica se realizó utilizando la solución de azul de lactofenol.

Para la identificación de las levaduras aisladas, se procedió a practicar la prueba de tubo germinal, haciendo una suspensión de la colonia en $0,5 \mathrm{ml}$ de suero humano fresco, que se incubó a $35^{\circ} \mathrm{C}$ durante 2 a 4 horas. Las colonias que resultaron positivas para la prueba de tubo germinal se consideraron como Candida albicans.

Los resultados se expresaron por orden de frecuencia de infección y etiología

\section{RESULTADOS}

En total fueron 80 pacientes mujeres con flujo vaginal que ingresaron a nuestra investigación.

Las edades de las pacientes de la muestra estudiada fluctuaron entre 25 y 45 años, edad media de $35 \pm 4$ años.

Según las características organolépticas de las muestras de secreción vaginal, la prevalencia de leucorrea con presencia de secreción de color amarillo verdoso fue de $23 \%$, blanco amarillento $15 \%$, blanco grisáceo $12,5 \%$.

Los resultados según la cantidad de secreción vaginal fue: regular en $58,8 \%$, escasa en $23,8 \%$ y abundante en $17,5 \%$ de PACIENTES. Según la consistencia de la secreción vaginal fue: espumosa en $41,3 \%$, homogénea-adherente en $31,3 \%$, grumosa en $27,5 \%$. Al evaluar las características del olor los resultados fueron: normal e inodora $42,5 \%$, mal oliente en $40 \%$ y olor a pescado en el $17,5 \%$ de las muestras. 
La prevalencia global de infección vaginal fue del 51,25\%, la prevalencia de vaginosis bacteriana como diagnóstico único fue de $12,5 \%$. EL agente etiológico aquí fue Gardnerella vaginalis, la prevalencia de candidiasis vaginal fue $11,25 \%$.

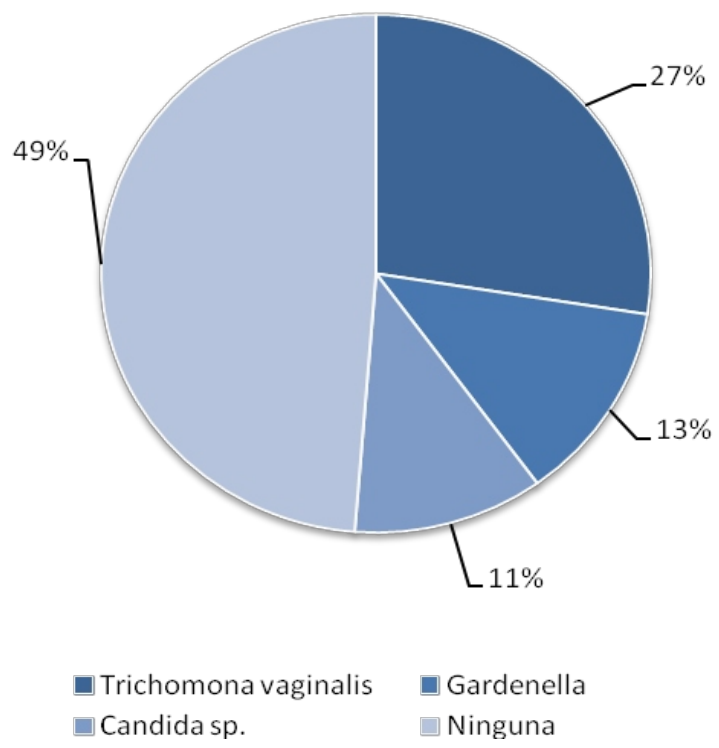

Figura 1. Prevalencia de vaginitis y vaginosis bacteriana en personal policial de Ica, Perú.

\section{DISCUSIÓN}

Los resultados obtenidos permitieron determinar los agentes etiológicos mas prevalentes para vaginitis y vaginosis bacteriana en el personal policial femenino de la provincia de Ica.

Este estudio concuerda con los hallazgos de Silva et al, quienes señalan que la Leucorrea puede presentarse a cualquier edad y que afecta a casi todas las mujeres durante algún tiempo de sus vidas; la edad es un factor muy importante en este tipo de procesos patológicos ya que durante los años de vida menstrual los microorganismos productores de vaginitis y por ende de leucorrea, frecuentemente son: Trichomonas vaginales, Gardnerella

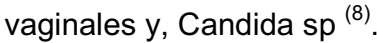

En el presente estudio las infecciones por Trichomona vaginalis fueron las más prevalentes en la población del personal policial femenino de la provincia de Ica, a diferencia de un estudio realizado en el Hospital Arzobispo Loayza donde la entidad etiológica más predominante fue Gardnerella vaginalis, probablemente debido a que dicho estudio se realizo en población de menor grupo etario ${ }^{(9)}$.
Tabla 1. Características de la muestras de secreción vaginal.

\begin{tabular}{lcc}
\hline \multicolumn{1}{c}{ Características } & $\mathbf{N}=\mathbf{8 0}$ & $\mathbf{( \% )}$ \\
\hline Color & 39 & $(48,8)$ \\
Blanquecina & 19 & $(23,8)$ \\
Amarillo verdoso & 12 & $(15,0)$ \\
Blanco amarillento & 10 & $(12,5)$ \\
Blanco grisáceo & & \\
Cantidad & 47 & $(58,8)$ \\
$\quad$ Regular & 19 & $(23,8)$ \\
Escasa & 14 & $(17,5)$ \\
Abundante & & \\
Consistencia & 33 & $(41,3)$ \\
Espumosa & 25 & $(31,3)$ \\
Homogénea-adherente & 22 & $(27,5)$ \\
$\quad$ Grumosa & & \\
Olor & 34 & $(42,5)$ \\
Normal & 32 & $(40,0)$ \\
Maloliente & 14 & $(17,5)$ \\
Pescado & \multicolumn{2}{c}{}
\end{tabular}

Es importante destacar que en los estudios donde se realiza el cultivo para trichomonas vaginalis se encuentra un porcentaje más elevado de este parasito, lo que permite concluir que el cultivo es más sensible para la detección de Trichomona vaginalis.

En nuestro estudio los resultados obtenidos, sobre la prevalencia de candidiasis vaginal en el personal policial femenino es menor respecto a los mostrados por otros estudios realizados en pacientes que asistieron, por ejemplo, a un centro médico de una zona rural de republica dominicana (48,8\%), así como de pacientes atendidos en el Hospital Arzobispo Loayza de Lima (16,2\%). Debemos tener en cuenta que el patógeno se encuentra en la flora normal de los pacientes pero, cuando disminuye la eficiencia del sistema inmunitario se convierte en un patógeno oportunista asociados a hábitos de higiene inadecuada ${ }^{(9,10)}$

Por otro lado, la prevalencia global de infección vaginal fue del $51,25 \%$ en nuestro estudio. Consideramos que uno de los posibles factores predisponentes sea el trabajo que tienen las femeninas por estar de pie controlando el tránsito vehicular, el uso de uniformes sintéticos, el calor de la ciudad de lca que llega a altas temperaturas, el desconocimiento de diferentes infecciones vaginales. 
Es necesario dar consejos para una correcta higiene intima femenina $y$, hacer que el organismo gubernamental regulador de medicamentos (DIGEMID) norme que se imprima una advertencia en los envases de los productos vaginales diciendo que las duchas vaginales son dañinas. Estas propician el ingreso de gran cantidad de gérmenes a los genitales internos. Es también necesario desarrollar investigaciones futuras para evaluar el efecto nocivo de las duchas vaginales en salud reproductiva y ginecológica.

Es prioritario recomendar a las mujeres: controles periódicos con el ginecólogo y, promover el examen ginecológico de secreciones vaginales para lograr un diagnostico precoz $Y$ tratamiento oportuno según el agente etiológico.

\section{AGRADECIMIENTOS:}

Agradezco la colaboración de los docentes de la E.P.G. de la UNICA y a su Director el Dr. Juan E. Ceccarelli Flores. por sus contribuciónes en este estudio.

Recibido: 12-4-11 Aprobado: 20-7-11

Financiamiento: El estudio fue autofinanciado Conflictos de interés: El autor declara no tener conflictos de interés en la publicación de este artículo

\section{REFERENCIAS BIBLIOGRÁFICAS}

1. Fosch S, Fogolín N, Azzaroni E, Pairetti N, D'ana L, Minacori H, Tita I, Redona M, Gribaudo G. Vulvovaginitis: correlación con factores predisponentes, aspectos clínicos y estudios microbiológicos. Rev Argent Microbiol 2006; 38(4): 202-205.

2. Chávez N, Molina H, Sánchez J, Gelaye B, Sánchez S. Duchas vaginales y otros riesgos de vaginosis bacteriana. Rev perú med exp salud publica 2009; 26(3):299-306.

3. Buscemi L, Arechavala A, Negroni R. Estudio de las vulvovaginitis agudas en pacientes adultas, sexualmente activas, con especial referencia a la candidiasis, en pacientes del Hospital de Enfermedades Infecciosas Francisco J. Muñiz. Rev Iberoam Micol. 2004; 21:177-81

4. García M, García S, Copolillo E, Cora M, Barata A, Vay C, Torres R, Tiraboschi N, Famiglietti A. Prevalencia de candidiasis vaginal en embarazadas. Identificación de levaduras y sensibilidad a los antifúngicos. Rev Argent Microbiol 2006; 38: 9-12.

5. Rodríguez I, Castellanos M. Diagnóstico y síntomas clínicos de la Tricomoniasis vaginal. Rev Cubana Obstet Ginecol 2002; 28(2): 93-99
6. Suárez M, Benítez N, Vega D, Barreto A. Factores de riesgo de infección por Trichomonas vaginalis en un área de saluid de la provincia Ciego de Ávila, Cuba. Rev Mex Patol Clin 2005; 52(3): 145-150.

7. Ciudad-Reynaud A. Infecciones vaginales por Candida: Diagnóstico y tratamiento. Rev Per Ginecol Obstet 2007; 53(3): 159-166.

8. Silva-Larralte $T$, Alarcón-Silva A, Ramírez $M$, Alarcón-Corredor $\mathbf{O}$. La leucorrea como motivo de consulta en el Ambulatorio Urbano I de Tucaní, Mérida, Venezuela. Rev Fac. Farm. 2002; 43: 2-6.

9. Medina $\mathbf{R}$, Rechkemmer A, García-Hjarles $\mathbf{M}$. Prevalencia de vaginitis y vaginosis bacteriana en pacientes con flujo vaginal anormal en el Hospital Nacional Arzobispo Loayza. Rev Med Hered 1999; 10(4): 144-149.

10. Feliz M, Pérez M, Beriguete A, Brito V, Almonte R. Prevalencia de candidiasis vaginal en la clínica rural La Jina, Yamasa (Monte Plata). Rev Med Dom 2005; 66(3): 247-248.

11. Duque C, Uribe $\mathrm{O}$, Soto A, Alarcón J. Candidiasis vulvovaginal en un grupo mujeres gestantes de Medellín. Infectio 2009; 13(1): 14-20

12. Rojas L, Solano R, Sariego I. Frecuencia de trichomoniasis en mujeres supuestamente sanas. Rev Cubana Hig Epidemiol 1999; 37(2): 66-70.

13. Buscemi L, Arechavala A, Negroni R. Estudio de las vulvovaginitis agudas en pacientes adultas, sexualmente activas, con especial referencia a la candidiasis, en pacientes del hospital de infecciosas Francisco J. Muñiz. Rev Iberoam Micol 2004; 21: 177181.

14. Guevara J, Béjar V, Cáceres A, Valencia E. Variedades de Candida en mujeres con flujo vaginal anormal. Anales Facultad Medicina, UNMSN 2000; 61(1): 51-54.

15. Di Gregorio G, Mendoza M. Incidencia de tricomoniasis vaginal en la consulta externa de ginecología. Boletín Médico de Postgrado 1996; 12(2).

16. González C. Flora vaginal en pacientes que asisten a consulta ginecológica. Rev Soc Ven Microbiol 2006; 26(1).

\section{Correspondencia:}

Bióloga Elizabeth Marleny Hernández Ríos Correo electrónico: elybio09@hotmail.com 